American Journal of Economics and Business Administration 3 (4): 645-651, 2011

ISSN 1945-5488

(C) 2011 Science Publications

\title{
Some Effects of Alternative Foreign Currency Translation Methodologies on two Short-Term Liquidity Ratios
}

\author{
Paul E. Holt \\ Department of Accounting and Finance \\ Texas A and M University, Kingsville, MSC 184 Kingsville, Texas 78363
}

\begin{abstract}
This study focused on two short-term liquidity ratios, the current ratio and inventory turnover and attempted to identify, in terms of empirical properties, if and in what ways foreign currency translation methodologies generate different results. Fifty companies' accounts were translated from U.S. dollars to U.K. pounds. Post-translation Spearman rank correlation coefficients were extremely high for all methodology pairs, but $t$ scores on meaningfully-paired observations indicated substantially different current ratio or inventory turnover numbers. But the results were not consistent from year to year and the results of all the fifty sample companies, taken together, did not hold for all the individual companies. At the firm level, the results were highly firm specific.
\end{abstract}

Key words: Foreign currency, post-translation samples, empirical properties, Spearman rank correlation coefficient, methodology pairs, Current-Noncurrent Method (CNC), Monetary-Nonmonetary (MNM), Temporal Rate Method (TRM), alternative translation, meaningfully-paired data, short-term liquidity ratios, inventory turnover

\section{INTRODUCTION}

Over several decades, a number of major changes in US generally accepted accounting principles regarding translation methods have occurred. Despite a massive translation literature, little empirical evidence is available to determine in what ways different translation methodologies provide different results. This study focuses on the two most commonly used shortterm liquidity ratios and attempts to identify, in terms of empirical properties, if and in what ways translation methodologies provide different results.

Literature review: There exists a massive foreign currency translation literature, spanning several decades, which consists largely of theory and opinions about how translation should or should not be done. Yet, little empirical research has been done to describe differences in information content of translated financial statements when different translation methodologies are applied. The translation policy choices for GAAP, in the U.S. as well as in other countries, have always been made with virtually no empirical knowledge of just what happens to consolidated financial statements when foreign accounts are translated by different methodologies.

During the period that the massive literature was being written, standard-setting bodies in the United States have required, at different times, four different translation methodologies. First, the CurrentNoncurrent Method (CNC) was required; then the Monetary-Nonmonetary (MNM) method advocated by Hepworth (1956) and required by APB Opinion No. 6 in 1965; then the Temporal Rate Method (TRM) developed by Lorensen (1972) and required in 1975 by SFAS \#8; and most recently the current rate method of SFAS \#52 (1981). But even this newer standard was criticized widely (for example, Beaver and Wolfson, 1982). Clearly there is no closure on the foreign currency translation and consolidation problem in the United States, let alone worldwide.

Classic, Relevant studies: The older foreign currency translation literature can be divided into four general categories: (1) studies which are surveys of management perceptions and changes in management behavior, (2) studies of the impact of alternative translation methods on financial statements, (3) market studies and (4) studies which reveal preferences for translation methods by studying events such as early adoption of SFAS \#52 and lobbying.

Among the category (1) studies, Griffin and Castanias (1987) observed that managers were motivated to enter the currency futures markets to reduce the fluctuations in reported translation gains and losses. This behavior, while functional for managers, can be dysfunctional to the company, since currency futures trading is costly. Bryant and Shank (1977) 
expected that such dysfunctional behavior would result in significant adverse market reaction.

Rodriguez (1980) surveyed seventy U.S. MNCs and found that managements were non-speculative, defensive with respect to exchange rate variations and reluctant to report translation losses. As a result, they were willing to pay a hedging cost higher than the average exchange depreciation. Houston (1986) found that managements decreased their financial exposure hedging when adopting SFAS \#52. A number of studies reflected managements' displeasure with currency translation rules. Examples are Choi et al. (1979) survey, Stanley and Block $(1979 ; 1980)$.

Among the category (2) studies are Aggarwal (1978), Biel (1976), Teck (1976), Porter (1983) and Selling and Sorter (1983), all of which criticized accounting rules for currency translation. Aggarwal (1978) and Reckers and Taylor (1978) expressed the opinion that SFAS \#8 resulted in financial statements that, in one way or another, did not reflect economic reality. In a simulation study, Rupp (1982) concluded that the temporal method of SFAS \#8 was extremely sensitive to the proportion of debt in the capital structure among the category (3) studies, Shank et al, (1979) and Ziebart and Kim (1987) observed various market reactions to currency translation methods. A conclusion to be drawn from category (3) studies is that accounting method does often result in an adverse market effect, although such effects are partially the result of managers' changes in behavior based on changes in accounting method.

Collins and Salatka (1993) concluded that including the foreign currency adjustment in reported earnings, as required by SFAS \#8 (TRM), produced noise which reduces the quality of earnings, but Soo and Soo (1994) found that the market reflected no difference between including the adjustment in earnings as required by SFAS \#8 and excluding it from earnings as required by SFAS \#52. Bartov (1997) found that the SFAS \#52 requirements caused reported earnings to be more relevant for market valuation than SFAS \#8.

Among the category (4) studies, Griffin (1983), Ayres (1986), Berg (1987), Kelly (1985) and others indicate that large companies with low management ownership are more likely to lobby for or against a proposed change in currency translation rules than smaller companies with higher management ownership.

More Recent Studies: The foreign currency translation literature is large and spans something like eight decades. Much of that literature is made up of theories and opinions and there are hardly any empirical studies that describe what actually happens when different translation methods are used and there are virtually no empirical studies which test different translation methods against any normative criterion.

During the past decade, a variety of foreign currency translation studies have appeared. Representative of these are the following:

Pinto (2002) applied game theory to observe evidence of a degree of managerial opportunism in currency translation method preferences and suggested a lack of clarity in FASB's classification scheme.

Louis (2003) empirically examined the association between changes in firm value and foreign translation adjustments for manufacturing companies. The study found that the translation adjustment is associated with a loss of value instead of an increase in value, because for firms in the manufacturing sector, GAAP for foreign currency translation generally produces results opposite to the economic effects of exchange rate changes.

Pinto (2005) tested the value relevance of foreign currency translation adjustments in an earnings and book value model and observed that foreign currency translation adjustments are significantly value relevant when their parameter estimates are allowed to vary in the cross-section.

Iatridis et a.l (2006) found that early adopters of the U.K. Statement of Standard Accounting Practice No. 20 'Foreign Currency Translation' were generally larger firms. Managements tended to adopt when the adverse economic consequences of adoption were likely to be minimal. They deferred adoption of the standard to influence their financial performance. The timing of the adoption is a matter related to the objectives of the managers in association with the market and economic conditions (Iatridis and Joseph, 2005). Income smoothing could be mitigated by appropriate standardization of accounting practice.

Iatridis (2005) empirically studied the U.K. stock market response to the implementation of the 1983 U.K. Statement of Standard Accounting Practice (SSAP) No. 20. The stock market appeared to have anticipated the implementation of SSAP 20. There was a positive stock market response in the official year of adoption, resulting from the income-stabilizing effects of the standard. The study also observed a significant relationship between stock returns and the accounting measures in the actual adoption period of the aggregate set of adopters.

Kwon (2005) showed that foreign investors generally price exchange risk differently from local investors and that the source and magnitude of differences in exchange risk pricing vary significantly across countries. 
Liu (2006) used an accounting-based equity valuation model for multinational firms to examine the forecasting and valuation properties of foreign currency translation gains and losses. The study found that translation gains and losses could be subdivided into a core component and a transitory component. The combined effect was that translation gains and losses were more transitory than transitory earnings.

Chambers et al (2007) provided evidence that other comprehensive income is priced by investors on a dollar-for-dollar basis. Two components of other comprehensive income, foreign currency translation adjustment and unrealized gains and losses on available-for-sale securities, were found to be priced by investors. But the study suggests that investors pay greater attention to other comprehensive information reported in the statement of changes in equity, rather than in a statement of financial performance.

Holt (2006) empirically compared the variability of reported earnings resulting from eight foreign currency translation methods. The current rate method with non-deferral of translation gains and losses resulted in the highest average variability of earnings and price parity methods resulted in lower variability than exchange rate methods as reflected by the average coefficients of variation of the study companies. However, results were highly firm specific. Holt (2005) examined the comparative information content of return on assets across translation methods.

\section{MATERIALS AND METHODS}

Methodology: The most serious obstacle to empirical research in foreign currency translation is that it is difficult to obtain a large sample of subsidiary companies for which the temporal characteristics of various accounts are known. This study overcomes this obstacle with the methodology described in this section:

- Fifty companies were selected to serve as a sample of pre-translation subsidiaries

- The temporal characteristics of the accounts of these companies were estimated. For a detailed description of how this estimation was achieved, see Petersen (1971), Davidson and Well (1976), Parker (1977). For a detailed description of how this step was achieved in the present study, see Holt (2012).

- The financial statements of each of the fifty companies were translated annually for a ten-year period (1996-2005) using three translation methodologies

- $\quad \mathrm{T}$ tests on meaningfully-paired data and Spearman rank correlation coefficients from the translated current ratio and inventory turnover numbers were calculated

The sample: It was impractical to take a sample of actual companies which were subsidiaries of a parent in another country and which required a translation of currencies prior to consolidation with the parent company. Numerous transactions are typical between parents and subsidiaries resulting in intercompany payables, profits and investments which must be eliminated in consolidation. Even if these transactions were disclosed and stand-alone financial statements of subsidiaries were available, it would not be known to what extent the use of a specific translation methodology affected management financing and operating decisions which in turn would have affected the financial statements.

In this study, U.S. companies were used as hypothetical subsidiaries of a British parent. An advantage of this procedure is that unknown effects of intercompany activity on the results of the study were precluded, since no intercompany transactions were present. The alternative choice would be to use British companies as hypothetical subsidiaries of a U.S. parent. In either case and in a real-world translation, the financial statements of the subsidiary would either be prepared or be recast into the GAAP of the parent company's environment. Neither recasting the financial statements of U.S. companies into British GAAP, nor recasting the financial statements of British companies into US GAAP was practical. Hypothetical US subsidiaries of British parents were selected instead of hypothetical British subsidiaries of US parents because financial statements of U.S. companies, along with the additional information required for translation, were more easily obtained. Further, the results of the study, using US GAAP, may be more relevant to accounting in the US.

The financial statements of fifty US companies were selected at random to build a data base of pretranslation financial statements. To be eligible for inclusion, a company must have had annual financial statements available for twenty consecutive years ending in 2005. The purpose of this criterion was to insure the availability of considerable information needed for this study that was not available from other sources, such as the cost of fixed assets acquired and retired. Although the study period was the ten years 1996-2005, financial data for 1986-2005 were needed to estimate the temporal characteristics of various accounts for the study period.

Translation: The financial statements of the fifty sample companies were translated, using three translation methodologies for each of the ten years in 
the study period. The translations were made from U.S. dollars to British pounds to form the post-translation samples. Although another currency could have been chosen, the time series data of exchange rates and purchasing power parity numbers between the U.S. and the U.K. were used because they were easily obtained and the U.K. is the largest single country direct investor in the U.S. and investee of the US.

The following three translation methodologies were selected for study:

- $\quad$ TRM (the temporal method of SFAS \#8)

- CRM (the current rate method of SFAS \#52)

- $\quad$ PPM (the price parity method)

The Current-Noncurrent Method (CNC) was excluded from this study, as the use of CNC and CRM produce the same current ratio and inventory turnover numbers.

Although the question of whether translation gains or losses should be included in current earnings (as required by SFAS \#8) or deferred (as required by SFAS $\# 52$ ) is an important translation question, it is irrelevant in the present study. Whether these gains or losses are deferred or not has no effect on the current ratio or the inventory turnover.

Since the 1974 Committee on International Accounting called for an investigation of a purchasing power parity theory-based approach as a possible alternative to exchange rate methods, the PPM was also included in this study. For a description of the purchasing power parity theory, see Officer (1982) and for a description of the price parity translation methodology, Patz (1977) and Patz (1981).

Although the Monetary-Nonmonetary Method (MNM), described in Hepworth (1956) was endorsed by the National Association of Accountants in 1960 and was GAAP prior to the issuance of SFAS \#8, MNM was excluded from the present study. MNM often results in the same translated numbers as TRM. The major potential difference between MNM and TRM is in the translation of inventories, although this difference occurs only when inventories are carried at market, a policy which few companies follow.

Ratios studied and empirical properties measured: A perusal of numerous accounting and finance textbooks reveals that the two most commonly-used shortterm liquidity ratios are the current ratio and inventory turnover. From the current ratio and inventory turnover ratio data, two tests were performed for each pair of translation methodologies: meaningfully-paired t-tests and Spearman rank correlation coefficients for each of the ten years in the study period.

\section{RESULTS AND DISCUSSION}

An unexpected, but important, observation was that use of the price parity method resulted in significantly lower variability of each of the two ratios than the use of the other two methods studied. This phenomenon was observed for nearly every company in the sample. In theory, the price parity numbers do not reflect the noise that is inherent in market-based exchange rates. Thus, it is possible that the use of the price parity method would actually reduce such noise and would result in more meaningful ratio numbers for analysts' use. Only further study can verify this interesting and very practical possibility.

In both Table 1 and Table $2, *$ indicates a t score significant at the $90 \%$ level of confidence. A positive $t$ score indicates the mean of the methodology first mentioned at the left was greater than the mean of the second methodology; a negative $t$ score indicates the opposite. For example, in 1997, PPM had a higher current ratio mean than CRM and TRM had a higher mean than PPM.

Table 1 indicates that the means of current ratios of the sample of fifty companies were not significantly different across methodologies with the exception of the TRM/PPM pair.

Table 1: T scores, meaningfully-paired comparisons Current Ratios, 1996-2005

\begin{tabular}{|c|c|c|c|c|c|c|c|c|c|c|}
\hline & 1996 & '97 & '98 & '99 & '00 & '01 & '02 & '03 & ’04 & '05 \\
\hline TRM/CRM & 0.2 & 0.8 & 0.8 & 1.1 & 1.0 & 0.5 & 0.2 & 0.1 & -0.7 & 0.8 \\
\hline TRM/PPM & $-2.0 *$ & $3.8^{*}$ & $2.8^{*}$ & $3.5^{*}$ & $3.8^{*}$ & 0.5 & -1.5 & $-2.1^{*}$ & -3.9 & $2.2 *$ \\
\hline CRM/PPM & -0.3 & -0.3 & -0.7 & -0.4 & -0.6 & -0.3 & -0.4 & -0.5 & -0.3 & -0.6 \\
\hline
\end{tabular}

Table 2: $\mathrm{T}$ scores, meaningfully paired comparisons Inventory Turnover, 1996-2005

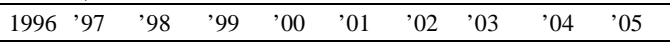
\begin{tabular}{llllllllll}
\hline TRM/CRM $4.4^{*}$ & $2.4^{*}$ & .3 & -1.2 & $3.0^{*}$ & $4.8^{*}$ & $5.4^{*}$ & $6.4^{*}$ & $5.0^{*}$ & $4.4^{*}$
\end{tabular}

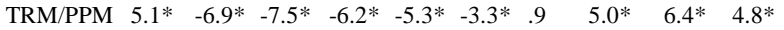
\begin{tabular}{lllllllllll}
$\mathrm{CRM} / \mathrm{PPM}$ & $-4.4^{*}$ & $-3.3^{*}$ & $-4.0^{*}$ & $-5.2^{*}$ & $-5.4^{*}$ & $-4.6^{*}$ & $-5.0^{*}$ & $-5.4^{*}$ & $-3.6^{*}$ & $-3.3^{*}$ \\
\hline
\end{tabular}

Table 3:Spearman rank correlation coefficients current ratio, 19962005

\begin{tabular}{lcccccccccc}
\hline & 1996 & '97 & '98 & '99 & '00 & '01 & '02 & '03 & '04 & '05 \\
\hline TRM/CRM & 0.94 & 0.94 & 0.97 & 0.98 & 0.98 & 0.98 & 0.97 & 0.94 & 0.91 & 0.95 \\
TRM/PPM & 0.99 & 0.99 & 0.99 & 0.98 & 0.98 & 0.97 & 0.99 & 0.98 & 0.99 & 0.99 \\
CRM/PPM & 0.91 & 0.97 & 0.96 & 0.95 & 0.96 & 0.95 & 0.95 & 0.97 & 0.93 & 0.97 \\
\hline
\end{tabular}

Table 4: Spearman rank correlation coefficients inventory turnover, 1996-2005

\begin{tabular}{lcccccccccc}
\hline & 1996 & '97 & '98 & '99 & '00 & '01 & '02 & '03 & '04 & '05 \\
\hline TRM/CRM & 0.91 & 0.93 & 0.93 & 0.94 & 0.94 & 0.92 & 0.90 & 0.84 & 0.82 & 0.91 \\
TRM/PPM & 0.99 & 0.99 & 0.99 & 0.98 & 0.96 & 0.98 & 0.99 & 0.99 & 0.99 & 0.99 \\
CRM/PPM & 0.88 & 0.89 & 0.89 & 0.88 & 0.87 & 0.85 & 0.90 & 0.86 & 0.84 & 0.88 \\
\hline
\end{tabular}


The meaningfully-paired $\mathrm{t}$ scores were significant for eight of the ten years in the study period for the TRM/PPM pair, although neither methodology resulted in consistently higher current ratios than the other over the entire ten-year period.

Some individual firms had results quite different from the fifty firms taken as a group. For all three methodology pairs, there can be found individual companies whose results, at least in some years, were opposite the group.

Table 2 suggests that the inventory turnover numbers were significantly different across methodologies. The signs of the $t$ scores across years suggest that either PPM or TRM resulted in the highest inventory turnover numbers and CRM.

In Table 2, as in Table 1, some individual firms had results quite different from the fifty firms taken as a group. For all three methodology pairs, there can be found individual companies whose results, at least in some years, were opposite the group.

These $\mathrm{t}$ scores suggest that these three translation methodologies may result in significantly different numbers, especially for the inventory turnover ratio. A more powerful test of the potential information content of the numbers generated by these three methodologies is the Spearman rank correlation coefficient. For example, two methodologies may generate two sets of observations with similar means, yet the rank orderings of companies may be significantly different. Conversely, two methodologies that generate two sets of observations with significantly different means may rank order companies similarly. Accordingly, Spearman rank correlation coefficients were calculated for each pair of methodologies and for each of the years in the study period.

The Spearman rank correlations among translation methodologies for the current ratios were extremely high as shown in Table 3, especially for the TRM/PPM pair, the two methodologies which, according to the $t$ scores, generated current ratios that were significantly different. The rank correlation coefficients for inventory turnover were also high, as shown in Table 4, despite significantly different inventory turnover numbers as indicated by the $t$ scores of Table 2 .

Clearly, different translation methodologies often generate substantially different current ratio and inventory turnover numbers. Further, the results are somewhat firm specific. Some individual companies' results did not match the pattern of the fifty sample companies taken as a group.

Table 5 indicates that the rank ordering of the three translation methodologies, based on the average current ratio measures of the fifty sample companies, changes from year to year. In six of the years of the ten-year study period, the use of TRM resulted in the highest current ratio measure of the three methodologies, PPM was second and CRM third. In three years, PPM replaced TRM as the methodology resulting in the highest average current ratio and in one year (2004) PPM was first, CRM second and TRM last.

Table 6 indicates similar results for inventory turnover. The rank ordering of the three translation methodologies, based on the average inventory turnover measure of the fifty sample companies, changes from year to year. In five of the ten years of the study period, the use of TRM resulted in the highest average inventory turnover, PPM the second highest and CRM the lowest. But in four other years PPM replaced TRM with the highest average inventory turnover and in one year (1999) CRM resulted in the highest average inventory turnover.

Table 5 and 6 indicate that the rank orderings of the average current ratios and average inventory turnovers are not consistent from year to year, although CRM nearly always results in the lowest average number for both ratios. Clearly it does matter which translation methodology is used.

A perusal of the individual company current ratio and inventory turnover numbers indicates that the yearly rank orderings of the three translation methodologies is highly firm specific.

Table 5: Rank-ordering of translation methodologies based on the average current ratio 1996-2005

\begin{tabular}{lllllllllll}
\hline Rank & 1996 & '97 & '98 & '99 & '00 & '01 & '02 & '03 & '04 & '05 \\
\hline 1 & PPM & TRM & TRM & TRM & TRM & TRM & PPM & PPM & PPM & TRM \\
2 & TRM & PPM & PPM & PPM & PPM & PPM & TRM & TRM & CRM & PPM \\
3 & CRM & CRM & CRM & CRM & CRM & CRM & CRM & CRM & TRM & CRM \\
\hline
\end{tabular}

Table 6: Rank-ordering of translation methodologies based on the average inventory turnover 1996-2005

\begin{tabular}{lllllllllll}
\hline Rank & 1996 & '97 & '98 & '99 & '00 & '01 & '02 & '03 & '04 & '05 \\
\hline 1 & TRM & PPM & PPM & CRM & PPM & PPM & TRM & TRM & TRM & TRM \\
2 & PPM & TRM & TRM & TRM & TRM & TRM & PPM & PPM & PPM & PPM \\
3 & CRM & CRM & CRM & PPM & CRM & CRM & CRM & CRM & CRM & CRM \\
\hline
\end{tabular}




\section{CONCLUSION}

Limitations and future studies: Although this is one of a very few existing empirical studies of alternative translation methodologies which use actual companies and actual exchange rates and price parity numbers, it is limited to short-term liquidity analysis. Further studies may produce substantially different results in other areas, especially any analyses involving reported earnings. Future studies of translated earnings must consider the deferral or non-deferral of translation gains and losses, a factor that was irrelevant in the present study.

This study is further limited to translations from U.S. dollars to U.K. pounds. It is not known whether the results would have been similar if other foreign currencies had been used.

Future studies should test the results of applying various translation methodologies against various normative criteria, so that the difficult question "Which translation methodology is best?" might eventually be answered.

\section{REFERENCES}

Aggarwal, R., 1978. FASB No. 8 and reported results of multinational operations: Hazard for managers and investors. J. Accoun. Auditing Finance, 97-216.

Ayres, F.L., 1986. Characteristics of firms electing early adoption of SFAS 52. J. Accoun. Econ., 143-158.

Bartov, E., 1997. Foreign currency exposure of multinational firms: Accounting measures and market valuation. Contemporary Accoun. Res., 14: 623-652. DOI: $\quad 10.1111 / \mathrm{j} .1911-$ 3846.1997.tb00544.x

Beaver, W.H. and M.A. Wolfson, 1982. Foreign currency translation gains and losses: What effect do they have and what do they mean? Finan. Anal. J., 28-36.

Berg, G.G., 1987. Early versus late compliance to SFAS 52: An Empirical Investigation of Firm Characteristics and the Market Response." Ph.D. Dissertation. Texas A and M University.

Biel, H.H., 1976. Foreign woes: Foreign Exchange Losses are Proving Costly for Many Multinationals. Forbes. December 1, 95.

Bryant, M. and J.K. Shank, 1977. FASB 8: Questioning the Economic Impact. The Accounting Forum. December, 11-29.

Chambers, D.J., T.J. Linsmeier, C. Shakespeare and T. Sougiannis, 2007. An Evaluation of SFAS No. 130 Compreehensive Income Disclosures. Review of Accounting Srtudies, Dec. Vol. 12 Issue 45: 557-593.

Choi, F.D.S., H.D. Lowe and R.G. Worthley, 1979. Accountors, accountants and standard No. 8. J. Int. Bus. Stud., pp: 81-87.
Collins, D.W. and W.K. Salatka, 1993. Noisy accounting earnings signals and earnings response coefficients: the case of foreign currency accounting. Contemporary Accoun. Res., 10: 119159. DOI: $10.1111 / j .1911-3846.1993 . t b 00385 . x$

Griffin, P.A. and R.P. Castanias, 1987. Accounting for the Translation of Foreign Currencies: The Effects of Statement 52 on Equity Analysts. Financial Accounting Standards Board of the Financial Accounting Foundation, Stamford, ISBN10:0910065225 pp: 112.

Griffin, P.A., 1983. Management's Preferences for FASB Statement No. 52: Predictive Ability Results. Abacus (Australia), 19: 130-139. DOI: 10.1111/j.1467-6281.1983.tb00244.x

Louis, H., 2003. The Value Relevance of the Foreign Translation Adjustment. The Accounting Review, 78: 1027-1047.

Hepworth, S.R., 1956. Reporting Foreign Operations. 1st Edn., Arno Press, New York, ISBN-10: 0405135246 pp: 211.

Holt, P.E., 2005. Comparative information content of return on assets based on alternative translation methods. Southwest Bus. Econ. J., 12: 9-17.

Holt, P.E., 2006. The variability of earnings across foreign currency translation methodologies: An empirical comparison. Bus. Econ. J., 13: 67-81.

Holt, P.E., 2012. Estimation of Temporal Characteristics of Accounts for Empirical Research. Advances Business Res., 2: 231-237.

Houston, C.O., 1986. U.S. Management Hedging Practices Subsequent to the Adoption of SFAS No. 52 'Foreign Currency Translation. Ph.D. dissertation. University of Washington

Iatridis, G., 2005. A conceptual framework of accounting policy choice under SSAP 20. Managerial Auditing J., 20: 763-778. DOI: 10.1108/02686900510611276

Iatridis, G.E. and N. Joseph, 2005. An Empirical Investigation of the UK Stock Market Response to the Implementation of SSAP 20 "Foreign Currency Translation". Investment Management Financial Innovations, $\quad 2$ 108-126. www.businessperspectives.org/journals_free/imfi/2 005/imfi_en_2005_01_Iatridis.pdf

Iatridis, G.E. and N.L. Joseph, 2006. Characteristics of UK firms related to timing of adoption of Statement of Standard Accounting Practice No. 20. Accounting Finance, 46: 429-455. DOI: 10.1111/j.1467-629X.2006.00176.X

Kelly, L., 1985. Corporate management lobbying on FAS No. 8: Some further evidence. J. Accoun. Res., 23: 619-632. 
Kwon, T.H. 2005. Do foreign investors price foreign exchange risk differently? J. Finan. Res., 28: 555573.

Liu, J., 2006. On international accounting valuation. J. Int. Accou. Res., 5: 67-87.

Lorensen, L., 1972. Reporting Foreign Operations of U.S. Companies in U.S. Dollars, Accounting Research Study. 1st Edn., American Institute of Certified Public Accountants, New York, pp: 118.

Officer, L.H., 1982. Purchasing Power Parity and Exchange Rates: Theory, Evidence and Relevance. 1st Edn., Jai Press, ISBN-10: 0892322292, pp: 361.

Parker, J.E., 1977. Impact of Price-Level Accounting. The Accou. Rev., 52: 69-96.

Patz, D., 1977. A price parity theory of translation accounting and business research.

Patz, D., 1981. Price Parity Translation: Methodology and Implementation. Accoun. Bus. Res., 207-216.

Petersen, R., 1971. An examination of the effects of changes in the general price level. Ph.D. Thesis, University of Washington.

Pinto, J., 2002. Foreign currency translation method choice: Insights from game theory. J. Applied Bus. Res., 18: 25-34.

Pinto, J.A., 2005. How comprehensive is comprehensive income? The value relevance of foreign currency translation adjustments. J. Int.

Porter, G.A., 1983. Foreign Currency Accounting FAS 8 or 52? Multinationals Experiment. Massachusetts CPA Rev.

Reckers, P.M.J. and M.E. Taylor, 1978. FASB No 8. does it distort financial statements? CPA J.
Rodriguez, R.M., $1980 . \quad$ Foreign-Exchange Management in U.S. Multinationals. 1st Edn., Lexington Books, Lexington, ISBN-10: 0669023302, pp: 128

Rupp, G.L., 1982. A Simulation Study of Alternative Methods for Translating Financial Statements of Autonomous Foreign Entities. 1st Edn., University Microfilms International, Ann Arbor, pp: 83 .

Selling, T.I. and G.H. Sorter, 1983. FASB Statement No. 52 and its implications for financial statement analysis. Finan. Anal. J., 39: 64-69.

Shank, J.K., J.F. Dillard and R.J. Murdock, . Assessing the Economic Impact of FASB 8: A Research Study. 1st Edn., The Foundation, New York, ISBN-10: 0910586314, pp: 143.

Soo, B.S. and L.G. Soo, 1994. Accounting for the multinational firm: Is the translation process valued by the stock market? Accou. Rev., 69: 617-637.

Stanley, M.T. and S.B. Block, 1979. Response by financial managers to No 8. J. Int. Bus. Stud.

Stanley, M.T. and S.T. Block. 1980. Accounting and economic aspects of SFAS No. 8. Int. Exe., 22: 810. DOI: $10.1002 /$ tie. 5060220205

Teck, A., 1976. International business under floating rates. Columbia J. World Bus.

Ziebart, D.A. and D.H. Kim, 1987. An examination of the market reactions associated with SFAS No. 8 and SFAS No. 52. Accou. Rev., 62: 343-357. 